\title{
ANALISIS TENSILE STRENGTH, BENDING, CANTABRO, DAN PERMEABILITAS PADA SPLIT MASTIC ASPHALT (SMA) DENGAN BAHAN TAMBAH HIGH DENSITY POL YETYLENE (HDPE) \\ Djoko Sarwono ${ }^{1)}$, F. Pungky Pramesti ${ }^{2}$, Hegar Lasardi Kurniawan ${ }^{3)}$ \\ 12) Pengajar Program Studi Teknik Sipil, Universitas Sebelas Maret \\ 3) Mahasiswa Program S1 Teknik Sipil Universitas Sebelas Maret \\ Roadmate Research Group Laboratorium Jalan Raya, Jl. Ir. Sutami No. 36 A Surakarta 57126 \\ Email:1)sarwono60@yahoo.co.id 2).t.pramesti@.ft.uns.ac.id 3)hegar.lasardi@gmail.com
}

\begin{abstract}
Split Mastic Asphalt (SMA) is one type of mixture of asphalt that has a gaps gradation. SMA mixture is usually used in heavy traffic, therefore there is often damage to the pavement such as cracks and deformation. HDPE (High Density Poly Ethylene) has thermoplastic properties that are elastic in hot and rigid in cold. HDPE is used to partially replace the no.4 aggregate in the mix. The purpose of this study was to analyze the mixed characteristics of SMA without HDPE and mixed SMA with HDPE addition. This study was conducted by testing ITS, Bending, Cantabro and Permeability, then the value of each test of each mix was compared. The result of the analysis shows that the mix of SMA with HDPE addition can increase the tensile strength value by 538\%, the value of bending strength increased by 293,05\%, the cantabro value decreased by $453,37 \%$, and the permeability coefficient value decreased by 224,5\% compared to mixed of SMA without HDPE

Keywords: 3 Point Bending, Cantabrian, Indirect Tensile Strength (ITS), Permeability, Split Mastic Asphalt (SMA).
\end{abstract}

\begin{abstract}
Abstrak
Split Mastic Asphalt (SMA) merupakan salah satu jenis campuran aspal yang memiliki gradasi senjang. Campuran SMA biasanya digunakan pada lalu lintas berat, oleh karena itu sering terjadi kerusakan pada perkerasan seperti retak dan deformasi. HDPE (High Density Poly Ethylene) memiliki sifat thermoplastik yaitu bersifat elastis pada saat panas dan bersifat kaku pada saat dingin. HDPE digunakan untuk mengganti sebagian agregat saringan no.4 pada campuran. Tujuan dari penelitian ini adalah untuk menganalisis karakteristik campuran SMA tanpa HDPE dan campuran SMA dengan tambahan HDPE. Penelitian ini dilakukan dengan menguji ITS, Bending, Cantabro dan Permeabilitas, kemudian nilai setiap pengujian dari masing-masing campuran dibandingkan. Hasil analisis menunjukkan campuran SMA dengan tambahan HDPE mampu meningkatkan nilai tensile strength sebesar 538\%, nilai kuat lentur meningkat sebesar 293,05\%, nilai cantabro berkurang sebesar 453,37\%, dan nilai koefesien permeabilitas berkurang sebesar 224,5\% jika dibandingkan campuran SMA tanpa HDPE.

Kata Kunci: 3 Point Bending, Cantabro, Indirect Tensile Strenght (ITS), Permeabilitas, Split Mastic Asphalt (SMA).
\end{abstract}

\section{PENDAHULUAN}

Jalan merupakan infrastruktur dasar dan utama dalam menggerakkan roda perekonomian nasional dan daerah, mengingat penting dan strategisnya fungsi jalan untuk mendorong distribusi barang dan jasa sekaligus mobilitas penduduk. Untuk itu diperlukan perencanaan struktur perkerasan yang kuat, tahan lama dan mempunyai daya tahan tinggi terhadap deformasi plastis yang terjadi.

Disisi lain, kehidupan manusia modern tidak terlepas dari barang-barang plastik yang banyak digunakan seharihari, contohnya pengemas makanan/minuman, pengemas peralatan elektronik, dan peralatan rumah tangga. Hasilnya jumlah sampah plastik pun ikut bertambah. Data tahun 2008 dari Deputi Pengendalian Pencemaran Kementerian Negara Lingkungan Hidup (KLH) menyebutkan, penumpukan sampah plastik mencapai 26.500 ton/hari. Penelitian yang dilakukan oleh F. Pamungkas tahun 2014 menyebutkan, HDPE (High Density Poly Ethylene) menyumbang sebesar $11 \%$ dari jumlah sampah plastik. Apabila diasumsikan dengan data dari KLH maka jumlah limbah plastik HDPE adalah 2.915 ton/hari.

Banyaknya jumlah limbah HDPE yang banyak ini perlu dimanfaatkan. Jumlah limbah plastik yang ada dapat dimanfaatkan dalam bidang konstruksi jalan. Salah satu pengembangan sistem perkerasan lentur adalah jenis campuran Split Mastic Asphalt (SMA). SMA adalah suatu lapisan permukaan tipis, mempunyai ketahanan yang baik terhadap alur (rutting) dan mempunyai durabilitas yang tinggi sehingga SMA cocok digunakan untuk lapisan permukaan jalan berlalu lintas berat (Wonson, 1996). Untuk menaikkan mutu campuran aspal, salah satu caranya adalah dengan menggunakan bahan tambah (additive). Additive adalah suatu komponen tambahan dari luar komponen utama dalam aspal beton yang dicampurkan sehingga dapat memberikan pengaruh yang positif didalamnya.

Pemanfaatan limbah HDPE sebagai additive diharapkan dapat merubah sifat-sifat fisik aspal dan meningkatkan stabilitas campuran dan ketahanan campuran terhadap deformasi. Deformasi adalah perubahan bentuk campuran aspal secara fisik. Deformasi pada aspal dapat ditinjau dengan beberapa uji laboratorium. Uji laboratorium yang dilakukan terdiri dari 4 uji yaitu ITS, Bending, Cantabro dan Permeabilitas. Uji ITS dan Bending untuk menganalisis 
nilai kekuatan campuran aspal yang telah dimodifikasi dengan limbah tutup botol plastik HDPE. Adapun pengujian lainnya untuk melihat ketahanan aspal adalah dengan pengujian Cantabro, untuk menganalisis bagaimana pengaruh penambahan material plastik HDPE terhadap disintegrasi campuran SMA. Pengujian terakhir adalah uji permeabilitas, karena material plastik yang bersifat kedap air sedangkan pada kondisi lapangan campuran aspal sering terkena hujan dan genangan, maka perlu dilakukan uji permeabilitas campuran untuk menilai apakah jenis modifikasi yang dilakukan ini dapat dilalui air atau tidak.

\section{Tinjauan Pustaka}

Adapun beberapa penelitian sebelumnya terkait dengan penambahan material plastik pada campuran aspal diantaranya:

- Tjitjik Wasiah Suroso (2004), menjelaskan pengujian campuran beraspal dengan tambahan LDPE menunjukan karakteristik Marshall naik 22,5\%, Stabilitas Dinamis naik 250\%, kecepatan deformasi turun $24 \%$ daripada campuran aspal tanpa penambahan plastik.

- Suryaman, F (2009), menjelaskan pada campuran aspal beton dengan penambahan plastik jenis PET, karakteristik Marshall seperti nilai Density, VFWA, dan Flow lebih rendah daripada campuran aspal beton normal. Sedangkan nilai stabilitas dan QM cenderung meningkat daripada campuran aspal beton normal.

- Aschuri, Yamin, dan Widyasih (2016), menjelaskan Penggunaan limbah plastik untuk menggantikan sebagian agregat dapat menambah nilai stabilitas, dan nilai kekuatan tarik (ITS).

- M. Fauzan Arofa (2017), menjelaskan Kadar aspal optimum pada campuran SMA dengan plastik sebagai pengganti aggregat adalah 6.95\% dengan kadar plastik optimum yang sebesar 33.5721\%.

\section{Dasar Teori}

Split Mastic Asphalt (SMA) merupakan salah satu jenis campuran aspal yang memiliki gradasi senjang pada agregatnya. SMA termasuk dalam Hot Mix Asphalt dimana terdiri dari dua penyusun yaitu agregat dan mortar pengikat. Pada campuran SMA juga perlu adanya bahan tambah (additive) berupa serat fiber sebanyak 0,3\% dari berat total campuran (NAPA, 1999). Spesifikasi SMA dapat dilihat pada Tabel 1. dan Tabel 2.

Tabel 1. Spesifikasi Campuran Split Mastic Asphalt (SMA)

\begin{tabular}{lll}
\hline Design Parameters-Marshall & & Note \\
\hline VTM $(\%)^{2}$ & $3-4$ & Marshall procedue are in accordence with AASHTO 245 \\
Asphalt Content $(\%)^{3}$ & Min.6 & VTM is based on AASHTO T-166, T-209 and T-269, Max \\
VMA $^{4}$ & Min 17 & density will be based on AASHTO t-209 \\
Stability, N(lbs) & $6200(1400)$ & Based on weight total mix \\
Flow 0,25mm $(0,01$ inch) & $8-16$ & VMA to be determined in accordance with TAI Manual \\
Compaction (number of blow) & 50 & Series No2 (MS-2) \\
Draindown $(\%)^{6}$ & Max 0,3 & See notes to the engineer \\
& & NCAT SMA Asphalt Draindown - See Notes to the \\
& & engineer\& appendix
\end{tabular}

(Sumber: National Asphalt Pavement Association)

Tabel 2. Spesifikasi gradasi campuran Split Mastic Asphalt (SMA)

\begin{tabular}{ll}
\hline Ukuran Saringan & Persentase Lolos Saringan (\%) \\
\hline $3 / 4$ in & 100 \\
$1 / 2$ in & $85-95$ \\
$3 / 8$ in & $75(\max )$ \\
No.4 & $20-28$ \\
No.8 & $16-24$ \\
No.30 & $12-16$ \\
No.50 & $12-15$ \\
No.200 & $8-10$ \\
$20 \mu \mathrm{m}$ & Kurang dari 3 \\
\hline
\end{tabular}

(Sumber: National Asphalt Pavement Association)

Menurut Wikipedia, HDPE (High Density Polyethylene) adalah polietilena termoplastik yang terbuat dari minyak bumi. HDPE memiliki kekuatan tarik yang tinggi. HDPE juga lebih keras dibandingkan jenis plastik lainnya dan bisa bertahan pada temperatur tinggi $\left(120^{\circ} \mathrm{C}\right)$. HDPE sangat tahan terhadap bahan kimia. 
Aspal didefinisikan sebagai material perekat (cementitious) berwarna hitam atau coklat tua, dengan unsur utama bitumen (Silvia Sukirman, 2007).

Indirect Tensile Strength (ITS) adalah sebuah pengujian gaya tarik tidak langsung yang bertujuan menganalisis karakter tensile dari campuran perkerasan.. Sifat uji ini adalah untuk memperkirakan potensi retakan pada campuran aspal. 3 Point Bending merupakan salah satu bentuk pengujian untuk menganalisis mutu suatu material secara visual. Selain itu uji bending digunakan untuk mengukur kuat lentur material akibat pembebanan. Cantabro adalah pengujian yang bertujuan untuk menganalisis ketahanan campuran aspal terhadap disintegrasi dengan menggunakan mesin Los Angeles. Permeabilitas adalah pengujian yang bertujuan untuk menganalisis nilai koefesien permeabilitas pada campuran aspal.

\section{METODE PENELITIAN}

Penelitian ini menggunakan 2 bentuk benda uji, yaitu silinder dan balok. Benda uji silinder digunakan untuk pengujian ITS, Cantabro, dan Permeabilitas. Khusus pengujian ITS tinggi benda uji dipotong menjadi $50 \mathrm{~mm}$. Benda uji balok digunakan untuk pengujian 3 Point Bending. Benda uji balok diperoleh dengan cara mencetak campuran pada mould balok berukuran $30 \times 25 \times 10 \mathrm{~cm}$ kemudian dipotong menjadi ukuran $25 \times 5 \times 5 \mathrm{~cm}$. Jumlah benda uji yang dibuat dapat dilihat pada tabel 3 .

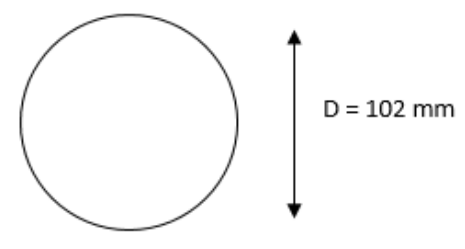

(a)

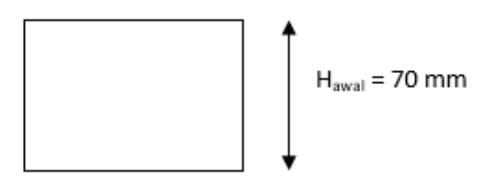

(b)

Gambar 1. (a) Diameter benda uji silinder (b) Tinggi benda uji silinder
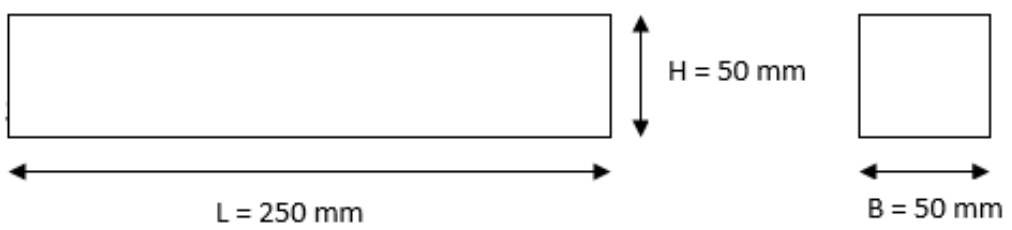

Gambar 2. Dimensi benda uji balok

Tabel 3. Jumlah benda uji

\begin{tabular}{cccccc}
\hline \multirow{2}{*}{ No } & \multirow{2}{*}{ Pengujian } & \multicolumn{2}{c}{ Silinder } & \multicolumn{2}{c}{ Balok } \\
& SMA Tanpa HDPE & SMA + HDPE & SMA Tanpa HDPE & SMA + HDPE \\
\hline 1 & ITS & 3 & 3 & - & - \\
2 & 3 Point Bending & - & - & 3 & 3 \\
3 & Cantabro & 3 & 3 & - & - \\
4 & Permeabilitas & 3 & 9 & 3 & - \\
& Total & 9 & 9 & - \\
\hline
\end{tabular}

\section{Pembuatan Benda Uji}

Pembuatan benda uji silinder menggunakan alat standard compaction dan benda uji balok menggunakan alat pemadat vibrator. Cacahan HDPE digunakan sebagai pengganti sebagian agregat no.4. Kadar aspal dan kadar HDPE menggunakan hasil penelitian yang dilakukan M. Fauzan, 2017. Kadar aspal optimum sebesar $6.95 \%$ dan Kadar HDPE optimum sebesar $33.5 \%$.

\section{Metode Pengujian}

Pengujian ITS dilakukan pada suhu $25^{\circ} \mathrm{C}$ dan kecepatan loading sebesar $51 \mathrm{~mm} /$ menit. Ketebalan sampel untuk uji ITS adalah $50 \mathrm{~mm}$. Pengujian 3 point bending menggunakan sampel berukuran $25 \times 5 \times 5 \mathrm{~cm}$ dengan suhu pengujian $25^{\circ} \mathrm{C}$. Pengujian cantabro dilakukan dengan memasukan sampel pada mesin Los Angeles satu persatu tanpa menggunakan bola baja kemudian diputar sebanyak 300 putaran dengan kecepatan 30-33 rpm. Pengujian permeabilitas menggunakan alat uji permeabilitas AF-16 dengan besar tekanan air sebesar $10 \mathrm{~kg} / \mathrm{cm}^{2}$.

\section{HASIL DAN PEMBAHASAN}


Hasil pemeriksaan material meliputi pengujian agregat, serat fiber, HDPE, dan karakteristik aspal. Seluruh hasil pengujian dapat dilihat pada Tabel 4. dan Tabel 5.

Tabel 4. Hasil pengujian agregat, serat fiber dan HDPE

\begin{tabular}{lll}
\hline Jenis Pengujian & Hasil & Satuan \\
\hline Keausan Aggregat & 25.42 & $\%$ \\
Berat Jenis Agg. Kasar & & \\
Bulk & 2.66 & $\mathrm{gr} / \mathrm{cc}$ \\
SSD & 2.68 & $\mathrm{gr} / \mathrm{cc}$ \\
Apparent & 2.71 & $\mathrm{gr} / \mathrm{cc}$ \\
Berat Jenis Agg. Halus & & \\
Bulk & 2.46 & $\mathrm{gr} / \mathrm{cc}$ \\
SSD & 2.51 & $\mathrm{gr} / \mathrm{cc}$ \\
Apparent & 2.60 & $\mathrm{gr} / \mathrm{cc}$ \\
Berat Jenis Serat fiber & 0.15 & $\mathrm{gr} / \mathrm{cc}$ \\
Berat Jenis HDPE & 0.96 & $\mathrm{gr} / \mathrm{cc}$ \\
\hline
\end{tabular}

Tabel 5. Hasil Pengujian Aspal

\begin{tabular}{llll}
\hline Jenis Pengujian & Hasil & Satuan & Spesifikasi \\
\hline Berat Jenis & 1.038 & $\mathrm{gr} / \mathrm{cc}$ & Min $1 \mathrm{gr} / \mathrm{cc}$ \\
Penetrasi & 62.5 & $\mathrm{~mm}$ & $60-70 \mathrm{~mm}$ \\
Titik Nyala & 290 & ${ }^{\circ} \mathrm{C}$ & $\geq 200^{\circ} \mathrm{C}$ \\
Titik Bakar & 336 & ${ }^{\circ} \mathrm{C}$ & $\geq 200^{\circ} \mathrm{C}$ \\
Titik Lembek & 48 & ${ }^{\circ} \mathrm{C}$ & $48-58^{\circ} \mathrm{C}$ \\
Daktilitas & 150 & $\mathrm{~mm}$ & Min $100 \mathrm{~mm}$ \\
\hline
\end{tabular}

\section{Kuat Tarik Campuran}

Pengujian ini menggunakan pendekatan sesuai dengan ASTM D 6931. Pada campuran SMA dengan HDPE nilai ITS mampu meningkat hingga 538\% dibandingkan campuran SMA tanpa HDPE.

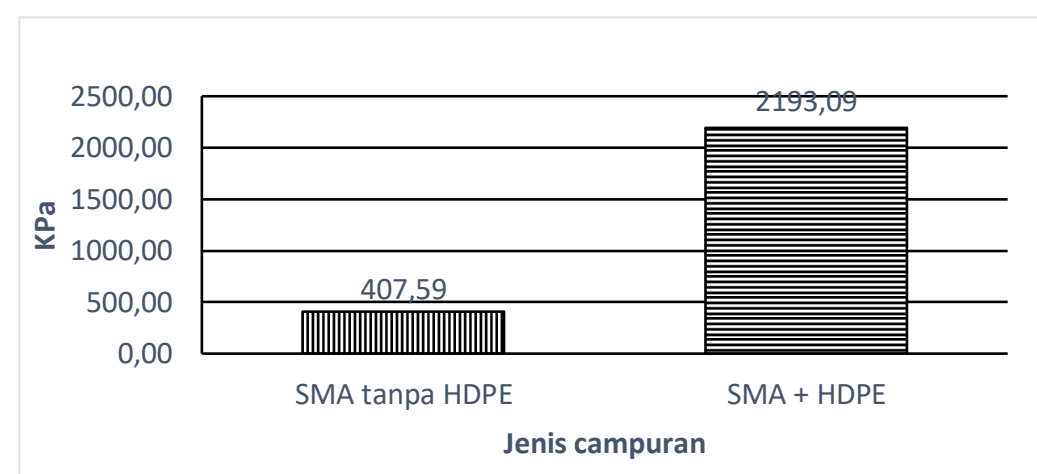

Gambar 3. Perbandingan Nilai Kuat Tarik

Peningkatan nilai ITS pada Campuran SMA dengan HDPE disebabkan oleh sifat HDPE yang memiliki sifat thermoplastik. Sifat thermoplastik menyebabkan HDPE menjadi kaku pada kondisi suhu ruang, sehingga mampu menghasilkan nilai kuat tarik yang lebih besar dibandingkan dengan campuran SMA tanpa HDPE.

\section{Kuat Lentur Campuran}

Pengujian ini menggunakan pendekatan sesuai dengan ASTM C 293-02. Pada campuran SMA dengan HDPE nilai kuat lentur mampu meningkat hingga 293.05\% dibandingkan campuran SMA tanpa HDPE. 


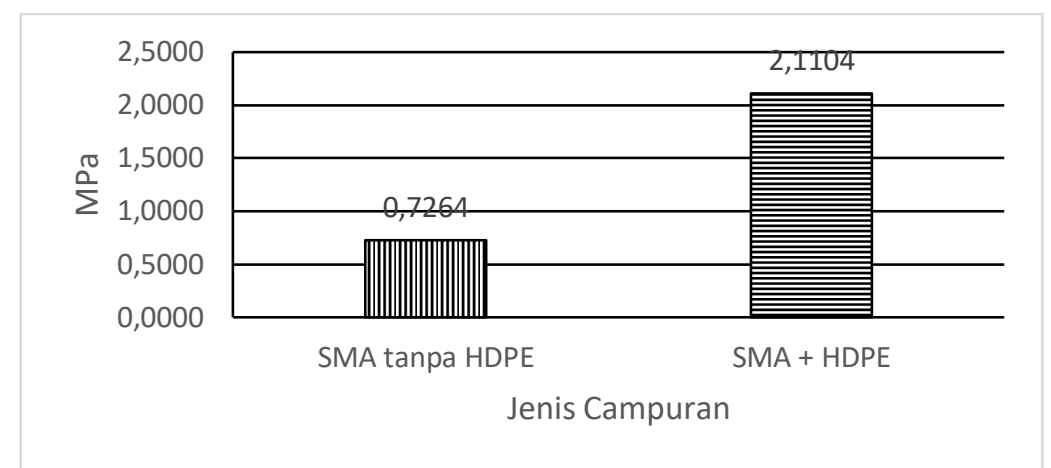

Gambar 4. Perbandingan Nilai Kuat Lentur

Peningkatan nilai kuat lentur pada Campuran SMA dengan HDPE disebabkan oleh sifat HDPE yang memiliki sifat lentur. Sifat lentur ini menyebabkan campuran menjadi lebih tahan terhadap gaya lentur, sehingga mampu menghasilkan nilai kuat lentur yang lebih besar dibandingkan dengan SMA tanpa HDPE.

\section{Ketahanan Campuran Terhadap Disintregrasi}

Pengujian ini menggunakan pendekatan sesuai dengan Tex-245-F. Pada campuran SMA dengan HDPE nilai Cantabro Loss menurun hingga 453.37\% dibandingkan campuran SMA tanpa HDPE.

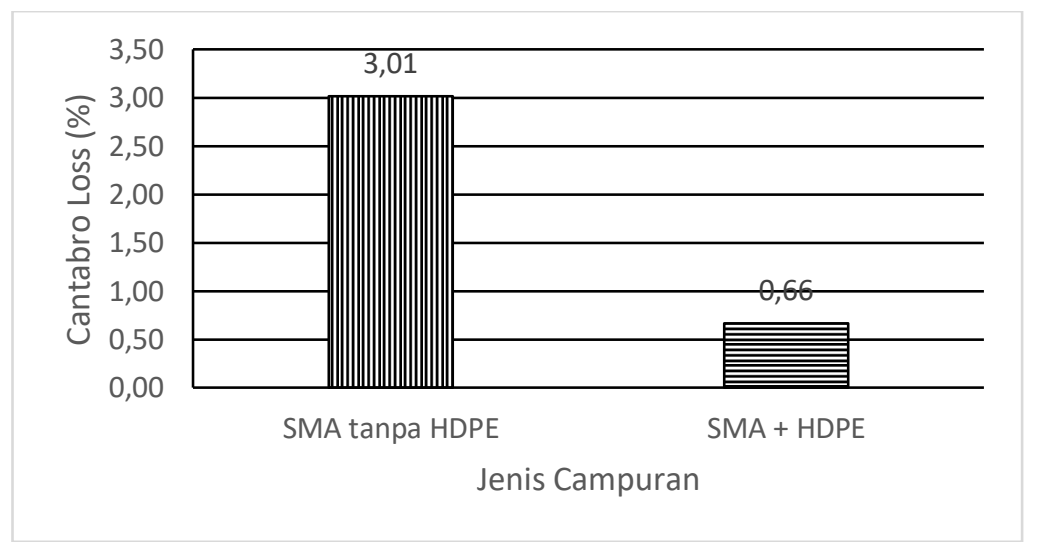

Gambar 5. Perbandingan Nilai Cantabro Loss

Penurunan nilai Cantabro Loss pada Campuran SMA dengan HDPE disebabkan oleh sifat HDPE yang memiliki sifat thermoplastik. Sifat thermoplastik menyebabkan lelehan plastik ketika dingin menjadi kaku, sehingga lelehan plastik mampu mengikat agregat lebih kuat.

\section{Karakteristik Permeabilitas Campuran}

Pengujian ini menggunakan alat uji permeabilitas tipe AF-16 dan dilaksanakan sesuai dengan buku pedoman manual. Pada campuran SMA dengan HDPE nilai koefesien permeabilitas menurun hingga $224.5 \%$ dibandingkan campuran SMA tanpa HDPE. 


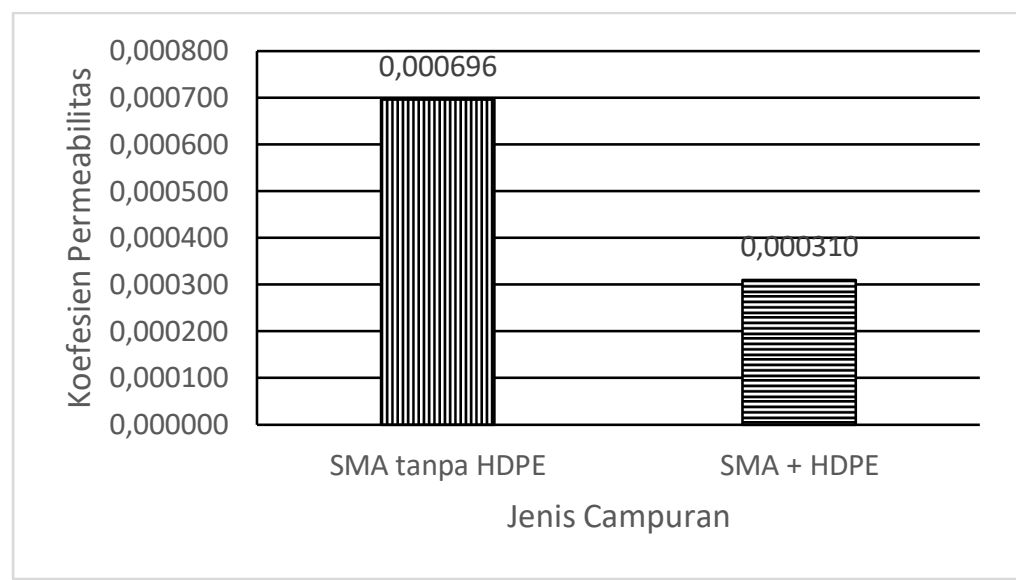

Gambar 6. Perbandingan Nilai Koefesien Permeabilitas

Hasil analisis terhadap nilai Koefesien permeabilitas menunjukkan bahwa kedua jenis campuran memiliki koefesien permeabilitas dengan klasifikasi Poor Drainage yang artinya kedua jenis campuran tidak cukup baik untuk dilewati air. Penurunan nilai koefesien permeabilitas disebabkan oleh sifat HDPE kedap air. Pada saat sebagian plastik meleleh, lelehan mengisi rongga pada campuran sehingga campuran menjadi impermeable pada sebagian daerah.

\section{SIMPULAN}

Berdasarkan hasil pengujian, maka didapatkan kesimpulan sebagai berikut:

a. Campuran Split Mastic Asphalt dengan modifikasi penambahan HDPE mampu meningkatkan nilai ITS sebesar $538 \%$. Dengan kata lain, campuran SMA dengan HDPE dapat menahan beban tarik lebih baik.

b. Campuran Split Mastic Asphalt dengan modifikasi penambahan HDPE mampu meningkatkan nilai Kuat Lentur sebesar 293,05\%. Dengan kata lain, campuran SMA dengan HDPE dapat menahan deformasi akibat beban lebih baik.

c. Campuran Split Mastic Asphalt dengan modifikasi penambahan HDPE mampu menurunkan nilai Cantabro Loss sebesar 453,37\%. Dengan kata lain, campuran SMA dengan HDPE dapat menahan kerusakan lebih baik.

d. Campuran Split Mastic Asphalt dengan modifikasi penambahan HDPE mengurangi nilai koefesien permeabilitas campuran sebesar $224,5 \%$. Menurunnya nilai koefesien permeabilitas dapat menyebabkan campuran mengalirkan air lebih baik pada permukaan jalan.

\section{REKOMENDASI}

a. Dengan nilai ITS dan Bending yang tinggi jenis campuran SMA dengan HDPE dapat menjadi alternatif perkerasan jalan pada simpang.

b. Dengan nilai disintegritas yang lebih kecil jenis campuran SMA dengan HDPE dapat digunakan pada jalur dengan lalu lintas padat.

\section{DAFTAR PUSTAKA}

AASHTO. 1993. Guide for Design of Pavement Structure: Washington DC.

Arofa, Fauzan. 2017. Analisis Optimum Bitumen Content Dan Suhu Pemadatan Optimum Pada Campuran Split Mastic Asphalt Dengan Limbah Plastik High Density Poly Ethylene (HDPE) Sebagai Pengganti Agregat

Menggunakan Marshall Test. Matriks Teknik Sipil. Universitas Sebelas Maret. Surakarta.

Aschuri, Imam, Anwar Yamin, and Yoseba Dani Widyasih. 2016. The Use of Waste Plastic as a Partial

Substitution Aggregate in Asphalt Concrete Pavement. Jurnal Teknik Sipil 23.1 Page: 1-6.

Fachrudin, Imam Hadi. 2016. Pengaruh Penambahan Plastik HDPE (High Density Poly Ethylene) Cara Basah

Dan Cara Kering Terhadap Kinerja Aspal Beton. Skripsi Jurusan Teknik Sipil-Fakultas Teknik UM.

Kurniawan, Ryan. 2016. Pengaruh Bitumen Modifikasi Ethylene Vinyl Cetete (EVA) Pada Asphalt Concrete dan

Thin Surfacing Hot Mix Asphalt (TSHMA) Terhadap Uji Kekesatan, UCS, ITS, Permeabilitas dan ITSM.

Matriks Teknik Sipil. Universitas Sebelas Maret. Surakarta.

NAPA. 2002. Designing and Constructing SMA Mixtures State of the Practice. Maryland: Forbes Boulevard

Sukirman, Silvia. 2007. Perkerasan Lentur Jalan Raya. Bandung: Nova.

Wantoro, Widi, Et Al. 2013. Pengaruh Penambahan Plastik Bekas Tipe Low Density Polyethylene (LDPE)

Terhadap Kinerja Campuran Beraspal. Jurnal Karya Teknik Sipil 2.4 Page: 366-381. 
Wonson K. 1996. Split Mastic Asphalt The European Experience. Paper at the 1996 AAPA Pavement Industry Conference, Asphalt Review. 